\title{
The Effect of Life Skills Intervention on Social Self Efficacy for Prevention of Drug Abuse Among Young Adolescent Students at Benha City
}

\author{
Hanan Abd Elwahab El Sayed ${ }^{1}$, Rasmia Abd El Sattar Ali ${ }^{2}$, Faten Mohamed Ahmed ${ }^{3}$, \\ Hedya Fathy Mohy ${ }^{4}$ \\ ${ }^{1}$ Health Nursing, Benha University, Benha, Egypt \\ ${ }^{2}$ Community Health Nursing, Ain Shams University, Cairo, Egypt \\ ${ }^{3}$ Psychiatric Mental Health Nursing, Benha University, Benha, Egypt \\ ${ }^{4}$ Community Health Nursing, Benha University, Benha, Egypt
}

Email address:

drfatenwafa@gmail.com (F. M. Ahmed)

\section{To cite this article:}

Hanan Abd Elwahab El Sayed, Rasmia Abd El Sattar Ali, Faten Mohamed Ahmed, Hedya Fathy Mohy. The Effect of Life Skills Intervention on Social Self Efficacy for Prevention of Drug Abuse Among Young Adolescent Students at Benha City. American Journal of Nursing Science. Vol. 8, No. 5, 2019, pp. 263-273. doi: 10.11648/j.ajns.20190805.19

Received: August 3, 2019; Accepted: August 21, 2019; Published: September 26, 2019

\begin{abstract}
Background. Young adolescent has to prepare for a global successful adult life of competition and independent functioning which is possible only through enhancing their psychosocial competencies through life skills training. As a health care provider, the school nurse is in a unique position to act as health educator, a change agent for youth substance abuse prevention. This study aims to evaluate the effect of life skills intervention on social self-efficacy for prevention of drug abuse among young adolescent students at Benha City. Methods. A quasi-experimental design was utilized. The study was conducted at two Preparatory Schools in Benha City (Benha Preparatory School for Boys and Benha Shared Preparatory School). Simple random sample of 120 students were included in the present study. Two tools were used for data collection; first tool. The Children's Self-Efficacy in Peer Interactions (CSPI). It was used to measure confidence in social interactions. Second tool; The Life Skills Training Questionnaire-Elementary Student (LSTQ-ES). This tool is designed to measure changes in knowledge, attitudes, and behaviors of elementary students related to social confidence and drug resistance skills. Results. The mean age of the studied students was $14.9 \pm 0.45$ years. There were statistically significant improvements $(\mathrm{P}<0.05)$ regarding to students' social self-efficacy in conflict \& non-conflict situations, life skills knowledge \& anti-smoking knowledge, anti-drinking and anti-smoking attitudes and life skills behaviors after the life skills intervention as compared to before. Conclusion. life skills intervention was efficient in improving students' social self-efficacy in conflict $\&$ non-conflict situations. also, knowledge of life skills \& anti-smoking knowledge, anti-drinking and anti-smoking attitudes and life skills behaviors were improved after implementation stage on young adolescent students. Recommendation. The school nurse should plan and perform constant life skills training workshops for students as effective tools of drug abuse prevention in schools.
\end{abstract}

Keywords: Life Skills, Social Self Efficacy, Drug Abuse, Students

\section{Introduction}

Adolescence is the period of transition from child hood to adulthood and from period under parental control to the independence during which major physical, cognitive, and psychological changes occur that may have impact on adolescent's life. This period of development is between the ages of 10 and 19 years. It is also a period of "storm and stress" for many adolescents. Though, biological forces play a significant role in the physical changes that takes place during this period. It is a time young people drift away and distance from parents. Spending more time with peers and conforming to the ideas and judgments of their peers. This transition is so crucial as they face problems in certain areas of life such as parent child conflicts, substance abuse, 
violence, risky behaviors and mood changes. If these issues are not resolved the individual suffers role diffusion or negative identity, which results in mismatched abilities and desires. [1-2]

Teenagers became involved in substance use at an early age, especially between 11 and 14years. Young people in this age range have little self-efficacy and resistance against substance use and are often unable to resist peer pressure attempts to use various substances. [3] The self-efficacy and helping adolescent to behave more rationally in the face of challenging life experiences is an effective factor in preventing the use of harmful substances such as alcohol and cigarette. However, if children and youth have not developed a positive self-efficacy, which is associated with self-esteem, they may become more vulnerable to a negative or risky response to experiences which require a strong self-efficacy. Individuals with low self-esteem have lower self-efficacy in resisting substance use. [4, 5]

Drug addiction is the root of insecurities in the society and poses threats to health and hygiene of the society as the whole. Due to medical, health, economic, social, and legal problems caused by drug abuse, the society needs to seriously pay more attention to effective preventive strategies. [6, 7] The trainings have been helpful for controlling smoking and drinking habits and drug abuse, preventing violence and crime, preventing suicide improving emotional and social adaptation, decreasing anxiety. [8]

Life skills training is a comprehensive and general program that actually deals with the skills that an individual needs to succeed in their adult lives like self-awareness, proper communication, problem solving, anger management, and handling stress are of the main concepts dealt in training. [9] Some examples also include teamwork, targeting and leadership. Such life skills can be seen as individual funds that improve educational states of young adolescent, life qualities and economic prosperity in their future lives. Public health programs should be directed targeting adolescents to prevent the onset of substance use and ultimately addiction in Egypt and elsewhere. [10, 11]

The adolescent has to prepare for a global successful adult life of competition and independent functioning which is possible only through enhancing their psychosocial competencies through life skills training. As a health care provider, the school nurse is in a unique position to act as health educator, a change agent for youth substance abuse prevention. School nurses have the opportunity to identify, address the impact both risk factors and protective factors within school, family and community liaison. [12]

\subsection{Conceptual Framework}

The conceptual framework underlying the current study builds on the Bandura's self-efficacy theory as it defined selfefficacy as an individual's judgment of their capabilities to organize and execute courses of action. It implies that people can exercise influence over what they do and, through reflective thought, a person can use knowledge and skills to perform specific behaviors. Social confidence implies perceived capabilities to execute a course of action in social interactions and suggested that judgment about an individual's self-efficacy is based on four informational sources enactive attainment, vicarious experience, verbal persuasion, and physiological feedback. [13]

Social support and social skills decrease vulnerability to stress, depression, physical illness, and poor health choices such as cigarette smoking, alcohol, and marijuana use, also through self-efficacy, perceived confidence in social capabilities will allow children to resist the pressure to engage in high risk activities such as drug use and early sexual activity. Botvin life skill training is one of the most widely disseminated drug prevention programs that improves self-esteem, decision-making skills, understanding harmful effects of tobacco use and misleading practices in advertising, and coping skills; and increase social confidence for resisting substance abuse and interacting positively with peers, social, and assertiveness skills. Life skill training extensively tested in a series of randomized trials and found effective in preventing cigarette smoking, alcohol, and drug use as well as violence and other health-risk behaviors. [14, 15]

Life skills training is one of the strategies proposed by the researchers. The term "life skills" refers to a large set of mental, social, and interpersonal skills that can help people make more informed decisions, effectively interact with others, enjoy physical-mental and social health, and deal with challenges and needs of their daily lives. [16]

\subsection{Significance of the Study}

Substance abuse is among the social challenges facing children. Children who lack social confidence and life skills are at risk for these and other socially deviant behaviors. Keeping children safe from drugs, violence, and bullying is a major goal of schools, communities, and health care providers. Evidence-based programs providing enhancement of social confidence and self-management of life skills during childhood are important for prevention of social problems such as peer violence and substance abuse. [17]

It is estimated that More than 1 in 5 of Egyptian university students used a substance at least once in their lives and the most common substances used by university students were cannabis $(83.4 \%)$, tramadol $(54.7 \%)$, and $(40 \%)$ using alcohol. In total, $59 \%$ of the students who used substance had either drug-related problems or dependence while Egyptian young adolescent school males ages 12-18 who reported smoking cigarettes were $(25 \%)$, water pipes $(15 \%)$, hashish $(6 \%)$, drinking alcohol (16\%), and taking Tramadol (3\%). $[18,19]$

Young adolescent must be equipped with life skills for social confidence, self-management, and protection against drug use to deflate the challenges of substance abuse. Asserted that socially confident children are more academically successful and poor social skills are a strong predictor of academic failure. IT has posited that development of self-esteem, social skills, and empathy improves social functioning of adolescent, so prevention 
programs should focus on development of self-control, emotional awareness, communication, and social problem solving and provision of academic support. [20] Therefore, the significance of this study can be reflected in its value in terms of continued research in this area, as well as what the results of this research will add to adolescents in schools, also it will open the way to many researchers to study new useful interventions for substance abuse. These data will help in the implementation of prevention and treatment programs in Egypt, and this fact emphasizes the importance of the current study.

\subsection{Aim of the Study}

To evaluate the effect of life skills intervention on social self-efficacy for prevention of drug abuse among young adolescent students at Benha City. This aim achieved through.

1. Assessing social self-efficacy, life skills \& anti-smoking knowledge and attitude of young adolescent students to identify their needs.

2. Designing and implementing life skills intervention according to young adolescent students' needs.

3. Evaluating the effect of life skills intervention on young adolescent students' self-efficacy knowledge, attitudes, and behaviors related to and drug resistance skills.

\subsection{Research Hypothesis}

Self-efficacy, knowledge, attitudes, and behaviors related drug resistance skills will be improved after implementation of life skills intervention on young adolescent students

\section{Subjects and Methods}

\subsection{Research Design}

A quasi-experimental research design (pre/post-test) was used to test the study hypothesis.

\subsection{Setting}

The study was conducted at two Preparatory Schools in Benha City (Benha Preparatory School for Boys and Benha Shared Preparatory School).

\subsection{Sample Type and Criteria}

Simple random sample technique was used in this study. Four classes from eighth grade and ninth grade have been chosen randomly from the previous two schools, then male students of these classes who scored average or below average in all the two tests as per the norms of the test and accepted to participate in the study were included in the intervention.

\subsection{Sample Size}

120 students from the previously mentioned settings were taken.

\subsection{Tools of Data Collection}

Two tools were translated into Arabic language and used to conduct the study.

\subsubsection{Tool I}

The Children's Self-Efficacy in Peer Interactions (CSPI). It was used to measure confidence in social interactions. Developed by Wheeler \& Ladd [21] the tool measures youths' perceptions of their ability to be successful in conflict and non-conflict social interactions. The tool was used before and after implementation of intervention and consists of 22 items that was scored on four point scale that consists of HARD!, Hard, Easy, and EASY! The students were instructed to choose HARD! if the social interaction was extremely hard and Hard if social interaction was less hard. The students were instructed to choose Easy if the social interaction was easy and EASY! if social interaction was extremely easy. The subscale items are summed to produce total scores. Items for efficacy in conflict situations subscale are $1,4,6,10,11,13,15,17,19,21$. Items for the nonconflict situations subscale are 2, 3, 5, 7, 8, 9, 12, 14, 16, 18, 20, 22. All 22 items can also be combined and summed to produce a total score of children's self-efficacy in peer interactions.

\subsubsection{Tool II}

The Life Skills Training Questionnaire-Elementary Student (LSTQ-ES). This tool is designed to measure changes in knowledge, attitudes, and behaviors of elementary students related to social confidence and drug resistance skills by National Health Promotion Associates [22] It was used before and after implementation of intervention and comprised of 42 items and involved four main sections.

1. Section A. Students' demographic data. This section assesses the student's birthday, gender, family structure, race and related variables ( 8 items)

2. Section B. Knowledge about life skills. This section includes 18 true/false items that assesses knowledge of various life skills training, two summary scores are produced. Anti-Smoking Knowledge and life skills knowledge. Summary scores reflect the number of knowledge items answered correctly. There is an overall knowledge score, as well as knowledge sub scores for anti-smoking knowledge and life skills knowledge.

3. To create an overall knowledge summary score, add up the number of items that are answered correctly and divide by 18 (the total number of knowledge items). This number gives you the proportion of knowledge items answered correctly.

4. To create anti-smoking knowledge summary score, add up the number of items (out of items 1-7) that are answered correctly and divide by 7 (the total number of drug knowledge items). This number gives you the proportion of drug knowledge items answered correctly.

5. To create life skills knowledge summary score, add up the number of items (out of items 8-18) that are answered correctly and divide by 11 (the total number of life skills 
knowledge items). This number gives you the proportion of life skills knowledge items answered correctly.

6. Section C. Pro-Smoking and Pro-Drinking Attitudes. This section includes 8 items that assesses positive attitudes regarding alcohol and tobacco use. The best answer for these questions is for students to disagree with the statements. To create an antismoking attitudes summary score, add the number of times students disagreed with items 1, 2, 3, and 7 and to create an antidrinking attitudes summary score, add the number of times students disagreed with items $4,5,6$, and 8 in. Higher scores indicate better attitudes.

7. Section D. The life skills assessment. This section includes 8 items that assesses behaviors associated with social confidence and self-management. There are eight life skills items. The best answer for these questions is for students to respond most of the time or very likely with the statements, and the second best answer is for students to respond some of the time or somewhat likely. To create a life skills summary score, give each item a score of 2 for "most of the time" or "very likely," and 1 for "some of the time" or "somewhat likely" and 0 for "never" or "not likely." Then add up the scores for the individual items. Higher scores indicate better life skills.

\subsubsection{Tools Validity}

The tools were revised for validity of the content by a panel of six experts, three in Psychiatric Mental Health Nursing and three in community health nursing field to ascertain relevance and comprehensiveness.

\subsubsection{Tools Reliability}

Cronbach's Alpha coefficient test was used to test reliability which displayed that the tools involved homogenous items as showed by the moderate to high reliability of each tool. The internal consistency for entire scale of Self-efficacy was $(\alpha=.85)$, for subscales $(\alpha=.73-.85)$, and for LSTQ-ES was 0.77.

\subsection{Ethical Considerations}

Before data collection, the participants were knowledgeable about the purpose of the study. They were given an chance to reject or to join in the study. Moreover, they were informed that, their collected information would be personal and used only for the purpose of the study.

\subsection{Pilot Study}

$10 \%$ of the sample (12) students was used for pilot study and were excluded from the study sample. The main purpose to assess the tools clarity and objectivity and estimate the time required to fill the tools of data collection.

\subsection{Field Work (Intervention Construction)}

A written approval to conduct this study after clarifying its purpose was taken from the Educational Administration in Benha and Undersecretary of the Ministry of Education.
Then written approval letter was given to the directors of the chosen schools. The study was carried out through four main phases. assessment, planning, implementation, and evaluation. These phases were carried out from beginning of July 2018 to the end of March 2019, covering along a period of 9 months. The previous settings was visited by the researchers two days/week (Sunday and Thursday).

\subsubsection{Assessment Phase}

The researchers interviewed the students during the school day. Upon consent to participate, students were interviewed to assess demographic data, Self-Efficacy in peer interaction, as well as The Life Skills. Students are asked to fill SelfEfficacy in peer interaction \& Life Skills Training Questionnaire-Elementary Student. The data attained during this phase considered the baseline for further comparisons to evaluate the effect of intervention on students. Time needed to complete of interviewing questionnaires ( 25 minutes). An average number of interviewed students / week 5 student.

\subsubsection{Planning Phase}

The intervention was designed by the researchers in a form of printed Arabic booklet to satisfy the young adolescents' deficit knowledge and skills and according to the goal of the intervention which was to prevent drug abuse by providing youth with the necessary knowledge and skills for improving social self-efficacy to resist social influences to use drug, as well as to reduce motivation to use these substances. A booklet was designed specifically for students, in simple Arabic language to suit their level of understanding. It educates students life skills. The main focus of the intervention was on teaching of information for drug resistance skills, personal self-management and general social skills for increasing overall competence and promoting the development of characteristics associated with decreased risk of using drugs in the future. It comprises teaching selfawareness, proper communication, problem solving, anger management, handling stress, self-esteem, decision-making skills, understanding harmful effects of tobacco use and misleading practices in advertising, and coping skills; and increase social confidence for resisting substance abuse and interacting positively with peers, social, and assertiveness skills. All are of the main concepts dealt in training.

\subsubsection{Implementation Phase}

During implementation phase the intervention was applied. The researchers explained the educational materials using appropriate strategies as follow. Teaching communication skills and being an active listener was taught to them practically and verbally and role playing was used for teaching this skill as two students were asked to talk to each other. In using solution instead of criticizing the students were asked to find a solution when a problem occurs instead of criticizing others (problem-solving skill). Teaching controlling anger through using distraction techniques (including counting, leaving the situation and so on), breathing from diaphragm (in which the individuals inhale while counting to the number 3 in their minds and then 
exhale slowly through mouth counting to the number 5), and relaxation were taught to the students. Teaching expressing emotions by using the sentence "I feel angered". Teaching creative thinking and using imagination when problems occurs. The students were asked to define their problems first when they occur and then imagine the solutions, finally employ them and innovate new solutions and take advantage of brainstorming. The intervention involved ten sessions which conducted to a small group (5-10) of the students (3045 minutes each). At the beginning of the first session an orientation to the intervention and its purpose taken place. Feedback was given at the beginning of each session about the previous one. Methods utilized to teach the content of the intervention included lectures, facilitation and group discussion, as well as cognitive-behavioural skills, modelling and practice. The central role of the intervention provider was to act as a skills trainer or coach because the intervention emphasized the acquisition of personal, interpersonal, and social resistance skills. Cognitive-behavioral skills were taught by combining instruction, demonstration, behavioural. rehearsal, social reinforcement and extended practice in the form of behavioural homework assignments.

\subsubsection{Evaluation Phase}

Evaluation was applied by comparing social self-efficacy, total knowledge scores and Pro-Smoking and Pro-Drinking Attitudes. The post-test was done three months after intervention to evaluate the effect of the implemented intervention.

\subsection{Statistical Analysis}

Data analysis was performed using Statistical Package for Social Sciences (SPSS version 20). Descriptive statistics were applied (e.g. frequency, percentages, mean, and standard deviation). Test of significance (paired $t$ test, $r$ test and chi-square test) was used to test the study hypothesis. Correlation coefficient was calculated between social selfefficacy, total knowledge scores, Anti-Smoking and Anti Drinking Attitudes and life skills behaviours. A significant difference was considered at $\mathrm{p}$-value $\leq .05$.

\section{Results}

Table 1. Distribution of the study participants according to their socio-demographic characteristics, and obstetric history. $(n=86)$.

\begin{tabular}{lll}
\hline Characteristics & No & \% \\
\hline Age & 18 & 15.0 \\
$14<15$ & 94 & 78.3 \\
$15<16$ & 8 & 6.7 \\
$16<17$ & $14.9 \pm 0.45$ & \\
Mean \pm SD & & \\
living with whom & 120 & 100.0 \\
Mother and father & & \\
Class & 20 & 16.7 \\
8th grade & 100 & 83.3 \\
9th grade & & \\
Grades get in school & 52 & 43.3 \\
Mostly A's (90-100) & 48 & 40.0 \\
Mostly B's (80-89) & 12 & 10.0 \\
Mostly C's (70-79) & 2 & 1.7 \\
Mostly D's (60-69) & 6 & 5.0 \\
D's or lower (less than 60) & & \\
\hline
\end{tabular}

Table 1: demonstrates demographic characteristics of the studied participants. It was clear that $78.3 \%$ of the studied students was aged from $15<16$ years, with a mean age $14.9 \pm 0.45$ years and all of the students living with mother and father. Moreover,
$83.3 \%$ of them were in the 8 th grade. Regarding students' grades in school, $43.3 \%$ of them mostly had A's (90-100) while only $5.0 \%$ of them had D's or lower (less than 60) More than half of them $(51.2 \%)$ reported insufficient monthly income.

Table 2. Distribution of the studied participants according to their life skills knowledge and anti-smoking knowledge (n=120).

\begin{tabular}{|c|c|c|c|c|c|c|c|c|c|c|}
\hline \multirow{3}{*}{ Items } & \multicolumn{4}{|c|}{ Pre-intervention } & \multicolumn{4}{|c|}{ Post-intervention } & \multirow{3}{*}{$\mathbf{X}^{2}$} & \multirow{3}{*}{ p-value } \\
\hline & \multicolumn{2}{|c|}{$\begin{array}{l}\text { Correct } \\
\text { answer }\end{array}$} & \multicolumn{2}{|c|}{$\begin{array}{l}\text { Incorrect } \\
\text { answer }\end{array}$} & \multicolumn{2}{|c|}{ Correct answer } & \multicolumn{2}{|c|}{$\begin{array}{l}\text { Incorrect } \\
\text { answer }\end{array}$} & & \\
\hline & No & $\%$ & No & $\%$ & No & $\%$ & No & $\%$ & & \\
\hline $\begin{array}{l}\text { life skills knowledge and anti-smoking knowledge } \\
\text { Cigarette smoking can cause your skin to wrinkle }\end{array}$ & 43 & 35.8 & 77 & 64.2 & 120 & 100.0 & 0 & 0.0 & 113.3 & $0.000 * *$ \\
\hline $\begin{array}{l}\text { Cigarette smoking can cause your teeth to turn yellow or } \\
\text { brown }\end{array}$ & 48 & 40.0 & 72 & 60.0 & 120 & 100.0 & 0 & 0.0 & 102.8 & $0.000 * *$ \\
\hline Cigarette smoking causes your heart to beat faster & 48 & 40.0 & 72 & 60.0 & 118 & 98.3 & 2 & 1.7 & 95.7 & $0.000 * *$ \\
\hline Smoking cigarettes can cause mouth cancer & 48 & 40.0 & 72 & 60.0 & 120 & 100.0 & 0 & 0.0 & 102.8 & $0.000 * *$ \\
\hline People who smoke cigarettes can usually stop anytime they & 82 & 68.3 & 38 & 31.7 & 118 & 98.3 & 2 & 1.7 & 38.8 & $0.000 * *$ \\
\hline
\end{tabular}




\begin{tabular}{|c|c|c|c|c|c|c|c|c|c|c|}
\hline \multirow{3}{*}{ Items } & \multicolumn{4}{|c|}{ Pre-intervention } & \multicolumn{4}{|c|}{ Post-intervention } & \multirow{3}{*}{$\mathbf{X}^{2}$} & \multirow{3}{*}{ p-value } \\
\hline & \multicolumn{2}{|c|}{$\begin{array}{l}\text { Correct } \\
\text { answer }\end{array}$} & \multicolumn{2}{|c|}{$\begin{array}{l}\text { Incorrect } \\
\text { answer }\end{array}$} & \multicolumn{2}{|c|}{ Correct answer } & \multicolumn{2}{|c|}{$\begin{array}{l}\text { Incorrect } \\
\text { answer }\end{array}$} & & \\
\hline & No & $\%$ & No & $\%$ & No & $\%$ & No & $\%$ & & \\
\hline \multicolumn{11}{|l|}{ want } \\
\hline Most teenagers smoke cigarettes & 86 & 71.7 & 34 & 28.3 & 120 & 100.0 & 0 & 0.0 & 39.6 & $0.000^{* *}$ \\
\hline Most adults smoke cigarettes. & 80 & 66.7 & 40 & 33.3 & 118 & 98.3 & 2 & 1.7 & 41.6 & $0.000^{* *}$ \\
\hline It's always best to make decisions quickly. & 34 & 28.3 & 86 & 71.7 & 16 & 13.3 & 104 & 86.7 & 8.18 & $0.004 *$ \\
\hline You should always let other people influence your decisions. & 22 & 18.3 & 98 & 81.7 & 6 & 5.0 & 114 & 95.0 & 10.3 & $0.001 * *$ \\
\hline Advertisements are always true. & 48 & 40.0 & 72 & 60.0 & 16 & 13.3 & 104 & 86.7 & 21.8 & $0.000 * *$ \\
\hline Stress can cause you to get sick & 51 & 42.5 & 69 & 57.5 & 112 & 93.3 & 8 & 6.7 & 71.1 & $0.000^{* *}$ \\
\hline $\begin{array}{l}\text { When you feel stressed, there is nothing you can do to stop } \\
\text { it. }\end{array}$ & 82 & 68.3 & 38 & 31.7 & 30 & 25.0 & 90 & 75.0 & 45.2 & $0.000^{* *}$ \\
\hline $\begin{array}{l}\text { We can tell how someone feels by the way he moves his } \\
\text { body without saying anything }\end{array}$ & 52 & 43.3 & 68 & 56.7 & 114 & 95.0 & 6 & 5.0 & 75.1 & $0.000^{* *}$ \\
\hline A good way to refuse to do something is to be assertive & 39 & 32.5 & 81 & 67.5 & 112 & 93.3 & 8 & 6.7 & 95.1 & $0.000^{* *}$ \\
\hline $\begin{array}{l}\text { A good way to be assertive by beginning your sentences } \\
\text { with the word "I". }\end{array}$ & 34 & 28.3 & 86 & 71.7 & 104 & 86.7 & 16 & 13.3 & 83.5 & $0.000^{* *}$ \\
\hline $\begin{array}{l}\text { "Peer pressure" means that an adult tries to get you to do } \\
\text { something you do not want to do. }\end{array}$ & 72 & 60.0 & 48 & 40.0 & 84 & 70.0 & 36 & 30.0 & 2.63 & 0.104 \\
\hline $\begin{array}{l}\text { There is nothing you can do about peer pressure except go } \\
\text { along with it. }\end{array}$ & 62 & 51.7 & 58 & 48.3 & 10 & 8.3 & 110 & 91.7 & 53.6 & $0.000^{* *}$ \\
\hline $\begin{array}{l}\text { When we feel bad about ourselves, it affects how well we do } \\
\text { in school, sports or other activities. }\end{array}$ & 41 & 34.2 & 79 & 65.8 & 108 & 90.0 & 12 & 10.0 & 79.4 & $0.000^{* *}$ \\
\hline
\end{tabular}

$\chi 2=$ Chi-squared test, * *tatistically significant difference at $\mathrm{P} \leq 0.000$

Table 2: declares that, a significant differences were present $(\mathrm{P}<0.000)$ before and after the intervention in relation to students' life skills knowledge and anti-smoking knowledge.

Table 3. Distribution of the studied participants according to their anti-smoking and anti-drinking attitudes before and after the intervention ( $n=120)$.

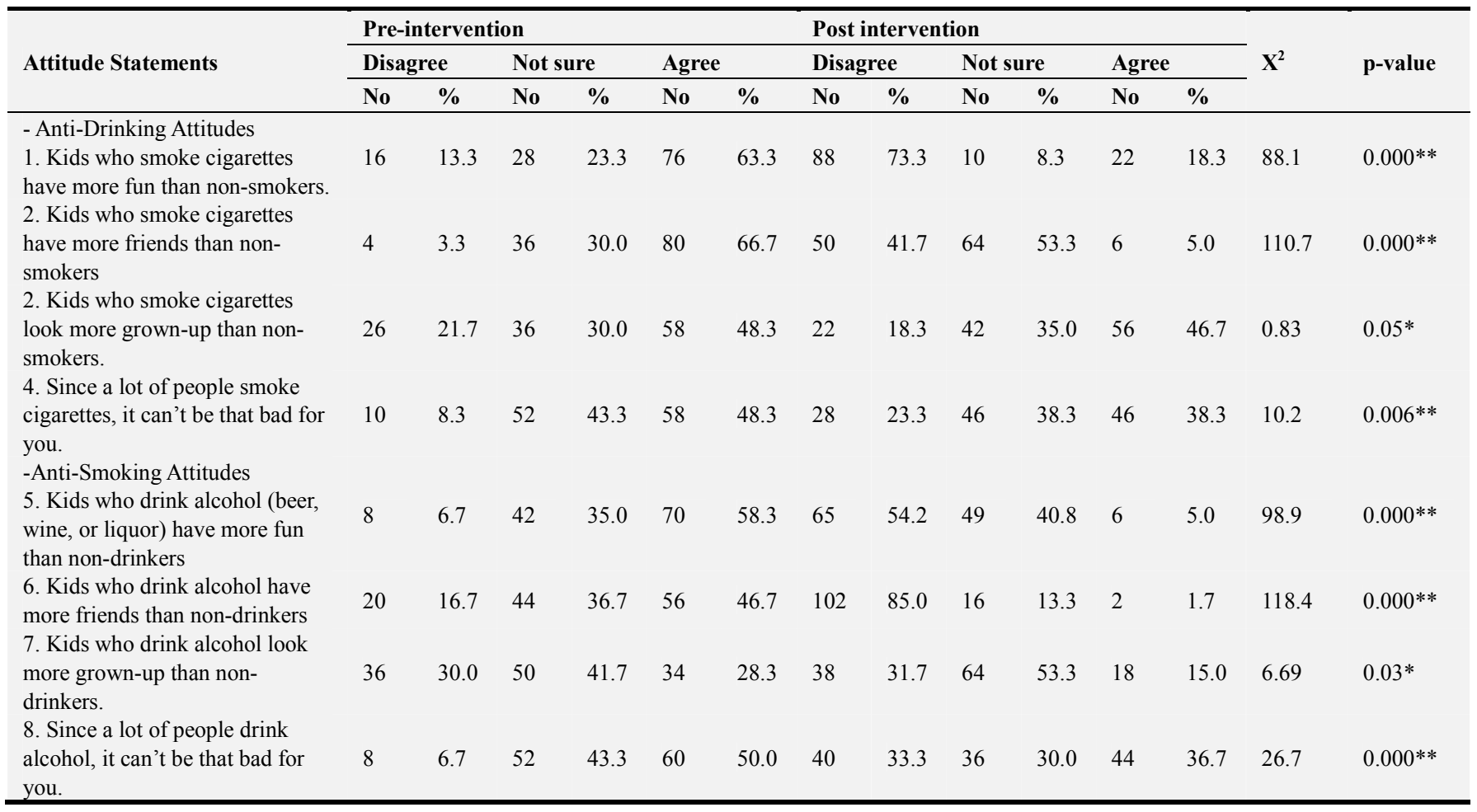

$\chi 2=$ Chi-squared test, ${ }^{*}$ statistically significant difference at $\mathrm{P} \leq 0.05$

Table 3: Displays significant differences $(\mathrm{P}<0.00)$ before and after the intervention in relation to all items related to antismoking and anti-drinking attitudes.

Figure 1 portrays that, $56.7 \%$ of the studied students had positive attitudes pre-intervention. Meanwhile post intervention the positive attitudes become $85.0 \%$. Moreover, there was a significant difference between results $(\mathrm{P}=0.05)$ before and after intervention. 


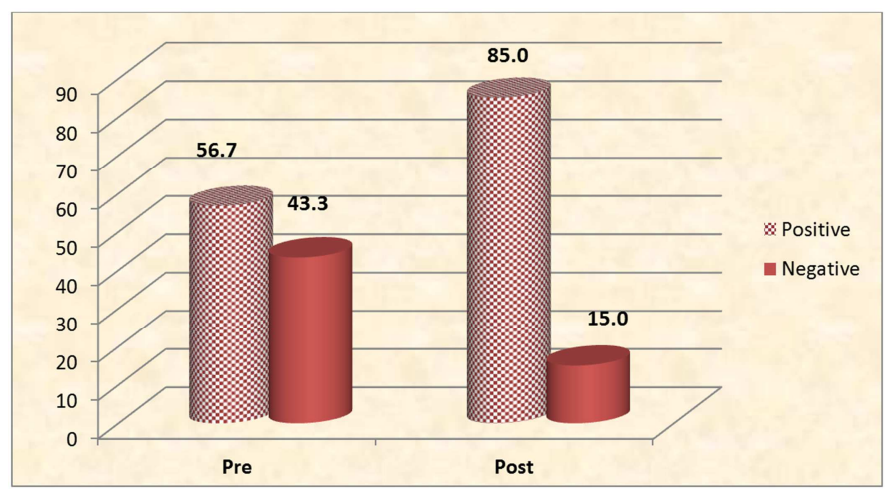

Figure 1. Distribution of the study subject according to their total attitudes pre and post-intervention $(n=120)$.

Table 4. Distribution of the studied participants according to their life skills behaviours before and after the intervention ( $n=120)$.

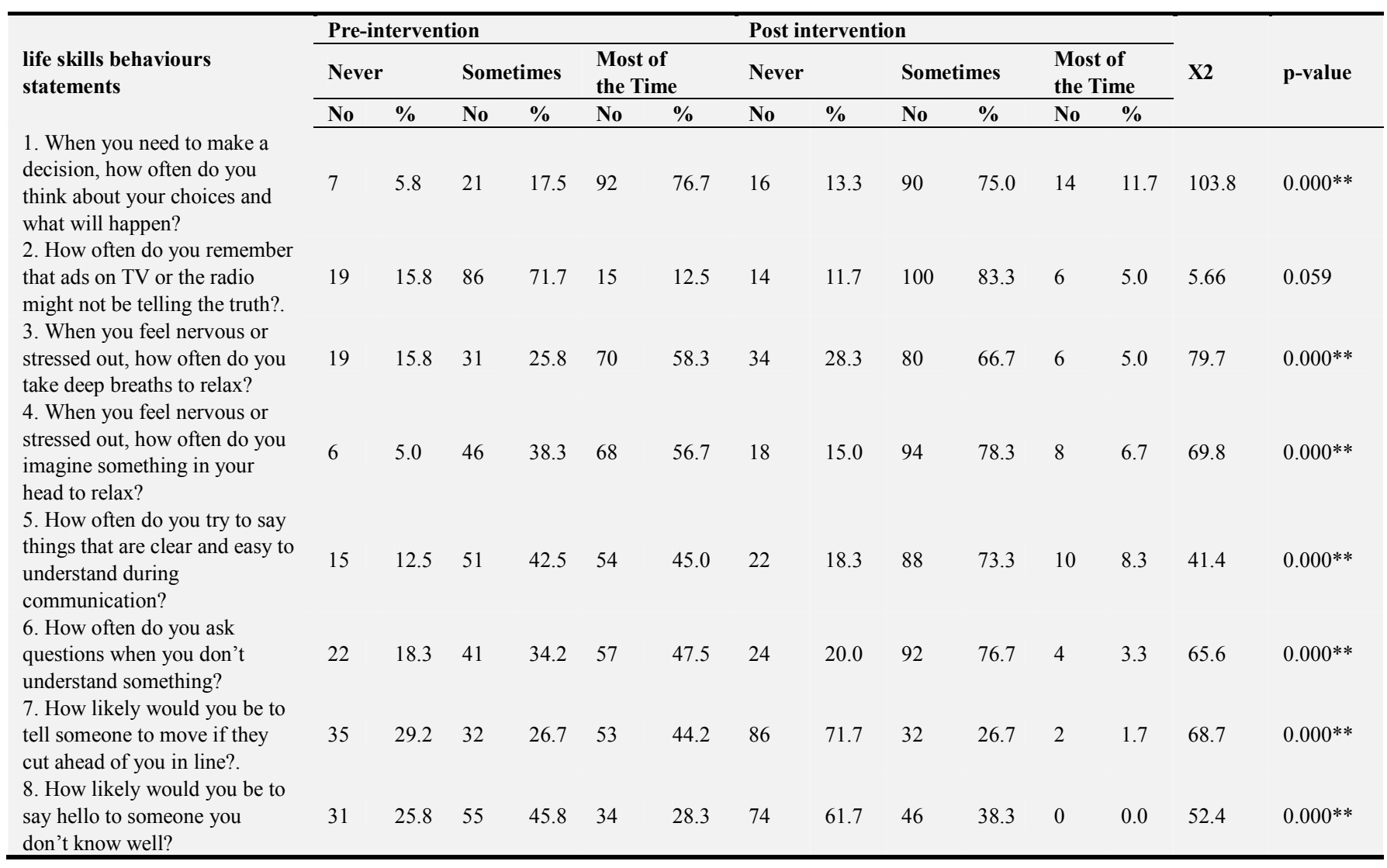

Table 4: clarifies that life skills behaviours were highly significantly different $(\mathrm{P}<0.000)$ before and after the intervention.

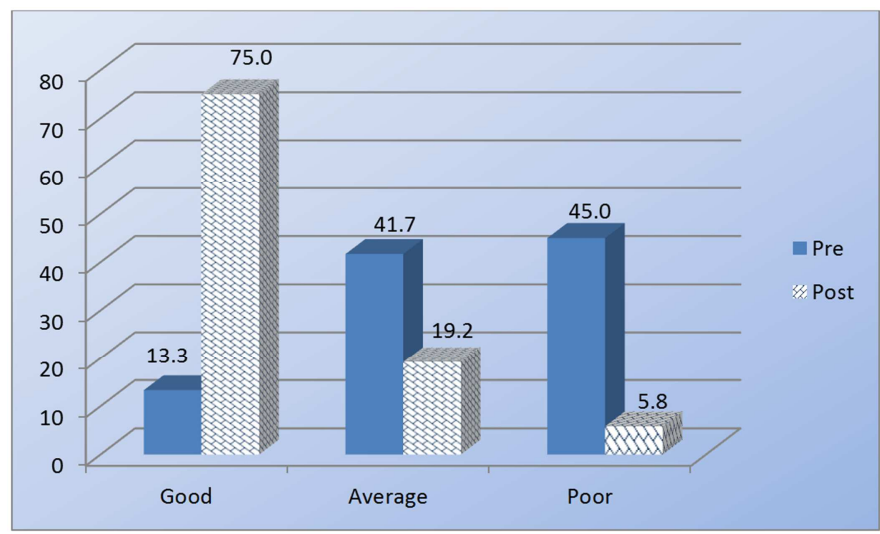

Figure 2. Distribution of the study subject according to their total life skills behaviours pre and post-intervention $(n=120)$. 
Figure 2: portrays that $75 \%$ of the studied students had good life skills behaviours pre-intervention. Meanwhile post intervention, $85.0 \%$ of the studied students had good life skills behaviours. Moreover, there was a significant difference between results $(\mathrm{P}=0.05)$ before and after intervention.

Table 5. Mean differences of self-efficacy scores of the study participants pre and post intervention $(n=120)$.

\begin{tabular}{|c|c|c|c|c|c|}
\hline Items & Maximum score & Pre-intervention & Post-intervention & Paired t test & P value \\
\hline \multicolumn{6}{|l|}{ self-efficacy scores } \\
\hline - Self-efficacy in conflict situation & 40 & $26.33 \pm 3.13$ & $32.68 \pm 4.20$ & 14.66 & $0.000 * *$ \\
\hline - Self-efficacy in non-conflict situation & 44 & $30.90 \pm 2.62$ & $38.80 \pm 5.36$ & 13.97 & $0.000 * *$ \\
\hline Total self-efficacy scores & 84 & $57.23 \pm 4.70$ & $71.48 \pm 9.27$ & 15.40 & $0.000 * *$ \\
\hline
\end{tabular}

** Highly statistically significant difference at $\mathrm{P} \leq .000$

Table 5: portrays general improvements $(\mathrm{P}=0.000)$ in the mean scores of self-efficacy after the intervention as compared to before intervention.

Table 6. Correlation coefficient between study subjects' subtotal scores of knowledge, attitude, life skills behaviours and their total Self-efficacy scores before and after intervention $(n=120)$.

\begin{tabular}{|c|c|c|c|c|c|}
\hline \multirow{3}{*}{ Variables } & & \multicolumn{4}{|c|}{ Self-efficacy scores } \\
\hline & & \multicolumn{2}{|c|}{ Pre-intervention } & \multicolumn{2}{|c|}{ Post-intervention } \\
\hline & & $r$ & $P$ & $r$ & $P$ \\
\hline \multirow{2}{*}{ Knowledge } & Pre-intervention & 0.24 & $0.007^{*}$ & & \\
\hline & Post-intervention & & & 0.28 & $0.002 * *$ \\
\hline \multirow{2}{*}{ Attitudes } & Pre-intervention & 0.028 & 0.758 & & \\
\hline & Post-intervention & & & 0.177 & $0.05^{*}$ \\
\hline \multirow{2}{*}{ Life skills behaviors } & Pre-intervention & 0.025 & 0.787 & & \\
\hline & Post-intervention & & & 0.38 & $0.000 * *$ \\
\hline
\end{tabular}

**Correlation is highly statistically significant at $(\mathrm{P} \leq 0.002)$

Table 6 indicates a positive correlation $(\mathrm{P}=0.002)$ between studied students' subtotal scores of knowledge and their total Self-efficacy scores before and after intervention, also a positive correlation between studied students' subtotal scores of attitude, life skills behaviours and their total Self-efficacy scores after intervention.

\section{Discussion}

Substance use in Egypt has been emerging as a public health problem with increasingly high prevalence among youth. ${ }^{[23]}$ During the first phases of adolescent development, youth are often exposed to several risky behaviors which can have lifelong social and health-related consequences. One of these behaviors involves is the experimental use of drug substances. A primary goal of public health officials is their commitment to the prevention of substance use among adolescent. A first step toward this goal is in the creation of interactive school programs for the 11 to 14 age group. It is important, therefore, to create educational programs for the 11 to 14 age group to prevent their introduction to substance use as much as possible. [24, 25] life skills educational program, it is currently recognized as a specific preventive program in many countries to deal with social damages such as addiction. [26] Therefore, the current study conducted with a view to evaluate the effect of life skills intervention on social self-efficacy for prevention of drug abuse among young adolescent students.

The current study results showed significant improvement in the post intervention stage on students' life skills and anti- smoking knowledge. This improvement of knowledge post intervention might be reflect the effect of the life skills intervention on increasing knowledge and awareness in this regard. These findings are in agreement with at least other four studies. First, Moradi et al. [27] They investigated the effect of drug abuse resistance and prevention skills training on 181 workers of Asalooyeh Petrochemical Company under two intervention and control groups. Results indicated the positive impact of training on the intervention group's knowledge and insight, drug abuse resistance skills, selfefficacy and decision-making in preventive actions. Second, Moshki et al. [28] who had conducted field trial experimental study on 60 students of Gonabad Medical University to study the effect of life skills training on drug abuse preventive behaviors among university students. Found that life skills training could either promote participant's knowledge about drug abuse preventive behaviors or decrease risk factors leading to drug abuse. Third, Nazarpoor et al. [29] They had reported claimed a promotion in the participants' knowledge and social skills and also a meaningful increase in the change of outlook toward drug abuse after attending workshops. Fourth, Williams et al. [30] their study findings demonstrated significant intervention effects on substance-use knowledge, attitudes, normative expectations, and general life skills among sixth and seventh grade adolescents who either participated in the life skill training CD-ROM prevention program.

An important finding from the current study is that antismoking and anti-drinking attitudes of the studied group was significantly $(\mathrm{P}<0.000)$ improved after intervention. In this 
regard Tymes, et al. [17] who had also applied life skills interventions to improve social confidence, self-management, and protection against drug use in rural elementary school aged children, and showed statistically significant difference $(\mathrm{P}<0.05)$ before and after intervention regarding the antismoking and anti-drinking attitudes and indicating the children reported improvements in antismoking and antidrinking attitudes. Moreover, findings of this study are also in line with the findings of study in Feredrick University by Buhler. [31] who demonstrated not only the preventive role of life skills training among non-smokers and non-drinkers but also its great impact on smokers and drinkers. Furthermore, Botvin et al. [32] who had examined the effectiveness of a substance abuse prevention program in preventing tobacco and alcohol use among elementary school students in grades 3 through life skills training. Found that intervention students at the posttest assessment reported less smoking in the past year $\mathrm{p}<.038$, higher anti-drinking attitudes, $p<.044$, increased substance use knowledge, $p$ $<.031$, and increased skills-related knowledge.

The finding of the current study showed statistically significant difference $(\mathrm{P}=0.000)$ before and after the intervention in relation to students' self-efficacy in conflict and non-conflict situations. This finding suggests that the life skills intervention motivate and develop self-efficacy and proves the effectiveness of the intervention. In this regard Muafi et al. [33] who had conducted an experimental research to investigates the role of life skills training in influencing self-efficacy, self-esteem, life interest and role behavior for unemployed youth in Paciran sub district. They found that there is a significant difference of self-efficacy before and after training. It means that an individual who involved in the training has different level of self-efficacy than who do not involved. Moreover, Gheitarani et al. [34] who had conducted a quasi-experimental study 462 male high school students of Silvana area in Urmia city, indicated that experiment group had significantly higher self-efficacy in compare with the control group. Teaching life skills to students increased their self-efficacy. Also, this finding in consistency with the results obtained by Lou, et al. [35] stating that teaching life skills is effective on increasing selfefficacy and decreasing risky behaviors of the students in experimental group. Also, previous studies by Vatankhah et al. [36] showed that teaching life skills has an effect on improving self-efficacy and the family performance in female-headed households. In addition, the study by Ghazavi, et al. [37] have shown that life skill training is a costeffective non-drug intervention to improve social, emotional, self-efficacy and educational performance. Furthermore, the study by Thomas \& Franz X. [38] has shown that their lifeskills-program influenced student's self-esteem positively and concluded that promotion of self-esteem should be linked with basic instruction about drugs and resistance self-efficacy training.

Additionally, the finding of current study pointed out that, life skills behaviours were highly significantly different $(\mathrm{P}<$ $0.000)$ before and after the intervention. This finding in the same line with the previously mentioned study by Moshki et al. [28] they demonstrating a significant improve in the posttest drug abuse preventive behaviors of intervention groups immediately after intervention than the control group. In other words, life skills training could successfully promote drug abuse preventive behaviors or reduce risk factors leading to drug abuse. In addition, the study of Tymes, et al. [17] agreed with our study findings indicating an improvement in the children life skills behavior score post intervention compared to pre intervention. Moreover, Jahanbin et al. [39] who had conducted a semi-experimental study to determine the effect of life skills training on social communication of male drug addicts who referred to Tavalod Novin Drug Clinic in Larestan, Iran. Their study findings indicated a positive significant relationship between life skills training to patients referring to drug clinics and improvement of their communication skills. In other words, an increase in life skills resulted in an improvement in the individual's communicational abilities. In addition, Pujar and Patil. [40] conducted a study on the life skills in the 1315 age group and found that these students who received education on life skills developed skills such as problem solving and stress coping.

The correlations between students' subtotal scores of knowledge, attitude, life skills behaviours and their total Selfefficacy scores before and after intervention were took place in the this study. Accordingly, there were a positive, significant correlations $(\mathrm{P}=0.002)$ between studied students' subtotal scores of knowledge and their total self-efficacy scores before and after intervention, also a positive correlation between studied students' subtotal scores of attitude, life skills behaviours and their total self-efficacy scores after intervention. These results were supported by at least two other researches. First, the previously mentioned Muafi et al. [33]. Found that an individual with high life skills will form a strong self-efficacy compared with an individual with low life skills, It means that there is a significant difference of self-efficacy before and after training. Second the previously mentioned Tymes et al. [17] who had reported that continuing the life skills training program using self-efficacy will reinforce life skills and using of self-efficacy is consistent with goals to improve social confidence in conflict and nonconflict interactions. Self-efficacy provides the framework for equipping adolescents with self-management and social and drug resistance skills. Given that the life skills intervention to prevent drug abuse is a novel preventive approach and regarding that promising results in different cultures and countries have been obtained by studies in Iran. ${ }^{[41]}$ and other countries. [42, 43]

\section{Conclusion}

Based on the results of the current study, it can be concluded that, the above mentioned findings proved and reinforced the research hypothesis. The life skills based intervention was efficient in knowledge, attitudes, and behaviors related drug resistance skills. The findings 
indicated a positive significant relationship between providing life skills training to students and improvement of their social self-efficacy. This has been observed in improving students' social self-efficacy in conflict \& nonconflict situations, life skills knowledge \& anti-smoking knowledge, anti-drinking and anti-smoking attitudes and life skills behaviors after implementation of life skills intervention on young adolescent students. The results also highlight the significance of life skills intervention as a useful framework for prevention of drug abuse among young adolescent students.

\section{Recommendations}

Based on findings of this study, the following recommendations can be proposed.

1. The school nurse should implement life skills interventions for students to promote their self-efficacy and drug resistance skills.

2. The school nurse should plan and perform constant life skills training workshops for teachers and students as effective tools of drug abuse prevention in schools.

\section{Further Study}

Evaluate the effectiveness of life skills interventions on social self-efficacy for prevention of drug abuse with long term follow up and larger sample size with different ages.

\section{References}

[1] Sawyer, S. M. et al. 'The age of adolescence,' in The Lancet Child \& Adolescent Health, 2018; 2 (3).

[2] Joy, M. \& Mathew, A., Emotional Maturity and General WellBeing of Adolescents, IOSR Journal Of Pharmacy, 2018; 8 (5). 01-06.

[3] Varela, A. \& Pritchard, M. E. Peer influence. use of alcohol, tobacco, and prescription medications. J Am Coll Health. 2011; 59. 751-756.

[4] Kadden RM, Litt MD. The role of self-efficacy in the treatment of substance use disorders. Addict Behav. 2011; 36. 1120-1126.

[5] Tse, S., Zhu, S., Yu, C. H., Wong, P. \& Tsang, S. An ecological analysis of secondary school students' drug use in Hong Kong. a case control study. Int J Soc Psychiatry. 2016; 62. $31-40$

[6] Akbari, K. The effect of life skills training on the social communication of clients referring to drug abuse clinic in larestan, iran 2015. Shiraz. Shiraz University of Medical Sciences; 2015.

[7] Lander L, Howsare J, Byrne M. The impact of substance use disorders on families and children. from theory to practice. Soc Work Public Health. 2013; 28 (3-4). 194-205. Doi: 10.1080/19371918.2013.759005. [PubMed. 23731414].

[8] Moshki, M., Hassanzade, T. \& Taymoori, P. Effect of Life Skills Training on Drug Abuse Preventive Behaviors among
University Students. Int J Prev Med. 2014; 5 (5). 577-83. [PubMed. 24932389].

[9] Jamali, S., Sabokdast, S., Sharif Nia, H., Goudarzian, A. H., Beik, S., Allen, K. A. The Effect of Life Skills Training on Mental Health of Iranian Middle School Students. A Preliminary Study. Iran J Psychiatry. 2016; 11 (4). 269-72. [PubMed. 28050189].

[10] Bailey, T., Jaggars, S. S., \& Scott-Clayton, J. Commentary. Characterizing the effectiveness of developmental education. A response to recent criticism. Journal of Developmental Education, 2013; 36 (3), 18.

[11] Loffredo, C. A., Shaker, Y, E., Jillson, I. A., Boulos, K., D. N, Saleh, D. A., Garas, M., et al, Prevalence and correlates of substance use by Egyptian school youth, IJADR, 2017, 6 (1), 37-51.

[12] Patestos, C., Patterson, K. \& Fitzsimons, V. M. Substance Abuse Prevention. The Role of the School Nurse Across the Continuum of Care, NASN School Nurse; 29 (6). 2014, 310314.

[13] Resnick, B. Self-efficacy. In S. J. Peterson \& T. S. Bredow (Eds.), Middle range theories, application to nursing research, 3rd ed., Philadelphia, PA. Lippincott Williams \& Wilkins, 2013; 84-85.

[14] Botvin, G. J., Life skills Training. Evidence-based prevention programs for schools, families, and communities. 2014, Retrieved from http://www.lifeskillstraining.com

[15] Fertman, C., \& Primack, B. (2009). Elementary student selfefficacy scale development and validation focused on student learning, peer relations, and resisting drug use. Journal of Drug Education, 2009; 39 (1), 23-38. Doi: 10.2190/DE.39.1.b.

[16] Akbari, K. The effect of life skills training on the social communication of clients referring to drug abuse clinic in larestan, iran 2015. Shiraz. Shiraz University of Medical Sciences; 2015.

[17] Tymes, D. D., Outlaw, K. L., \& Hamilton, B. K., Life Skills Interventions to Improve Social Confidence, SelfManagement, and Protection against Drug Use in Rural Elementary School Aged Children, Journal of Community Health Nursing, 2016; 33. 1, 11-19, DOI: 10.1080/07370016.2016.1120592.

[18] Bassiony, M. M., Salah El-Deen, G., Abdelghani, M. \& ElGohari, H., Addressing prevalence and correlates among a sample of Egyptian university students who suffer from substance use disorders, Addictive disorders \& Their treatment, 2018; 17 (3). p 114-123.

[19] Loffredo, C. A., Shaker, Y, E., Jillson, I. A., Boulos, K., D. N, Saleh, D. A., Garas, M., et al, Prevalence and correlates of substance use by Egyptian school youth, IJADR, 2017, 6 (1), $37-51$.

[20] Lipman, E., Kenny, M., Brennan, E., O’Grady, S., \& Augimeri, L. Helping boys at risk of criminal activity. Qualitative results of a multi-component intervention. BioMed Central Public Health, 2011; 11 (364), 1-11. Doi: 14712458/11/364.

[21] Wheeler, V., \& Ladd, G. Assessment of children's selfefficacy for social interactions with peers. Developmental Psychology, 1982; 18 (6), 795-805. Doi: 10.1037/00121649.18.6.795. 
[22] National Health Promotion Associates. (2018). Life skills training questionnaire elementary school version instruction guide, 2-6. Retrieved from http://www.lifeskillstraining.com

[23] United Nations Office on Drugs and Crime (UNODC). (2012). World Drug Report 2012. Retrieved from http://www.unodc.org/unodc/en/data-and-analysis/WDR2012.html

[24] Mayberry, M. L. Espelage DL, Koenig B. Multilevel modeling of direct effects and interactions of peers, parents, school, and community influences on adolescent substance use. J Youth Adolesc. 2009; 38. 1038-1049.

[25] Chakravarthy, B., Shah, S., Lotfipour, S. Adolescent drug abuse - awareness and prevention. Indian J Med Res. 2013; 137. 1021-1023. United Nations Office on Drugs and Crime.

[26] Moshki, M., \& Aslinejad, M. A. The life skills training and preventive behaviours of substances Abuse among university students. A longitudinal study. J of Fasa Univ of Med Sci. 2013; 3 (3). 194-201.

[27] Moradi, M., Heydarinia, A. R., Babayi, G. R., Gehangiri, M. Stage-based interventions for drug abuse prevention among petrochemical workers in assaluyeh. Med Sci J Islam Azad Univ Tehran Med Branch. 2009; 19. 246-55.

[28] Moshki, M., Hassanzade, T., \& Taymoori, P. Effect of Life Skills Training on Drug Abuse Preventive Behaviors among University Students. Int J Prev Med., 2014; 5 (5). 577-583.

[29] Nazarpoor, M., Pouzesh, S. D., Raoufi, M. B., Sadagat, K., Nazari, M., Amini, A., et al. Effect of life skills workshops on changing the attitudes and awareness toward narcotic drugs abuse in students. J Tabriz Univ Med Sci. 2010; 31. 83-6.

[30] Williams, C., Griffen, K., Macaulay, A. B., West, T. L., \& Gronewold, E., Efficacy of a Drug Prevention CD-ROM Intervention for Adolescents, Substance Use \& Misuse, 2005; 40. 869-877.

[31] Buhler, A., The role of life skills promotion in substance prevention. Mediation analysis Friedrich Schiller University. 2007. [Last accessed on 2012 Mar 02]. Available from. $\mathrm{http} / / / \mathrm{www}$. file.//1the role of life skills Prevention.html

[32] Botvin, G. J. \& Griffin, K. W., Paul, E., \& Macaulay, A. P. Preventing tobacco and alcohol use among elementary school students through life skills training, Journal of Child \& Adolescent Substance Abuse, 2003; 12 (4). 1-17.

[33] Muafi, Hartati, A. S., \& Gusaptono, H., The Role of Life Skills Training on Self-Efficacy, Self Esteem, Life Interest, and Role Behavior for Unemployed Youth, Global Journal of Management and Business Research, 2010; 10 (1). 132-139.
[34] Gheitarani, B., Imani, S., Sadeghi, N., \& Ghahari, S. H., Effectiveness of life skills training on self-efficacy and emotional intelligence among high school students in Urmia, $\begin{array}{lllll}\text { SDH., } & 2017 \text {; } 3 & \text { (3). } & 160-166 . & \text { DOI. }\end{array}$ http://dx.doi.org/10.22037/sdh.v3i3.18053

[35] Lou, Ch. H., Wang, X. J. Tu. X. \& Gao, E. Impact of Life Skills Training to Improve Cognition on Risk of Sexual Behavior and Contraceptive Use among Vocational School Students in Shanghai, China. Journal of Reproduction \& Contraception. 2008; 239-251.

[36] Vatankhah, H., Daryabari D, Ghadami. V\& Khanjan, Sh. E. Teaching how life skills (anger control) affect the happiness and self-esteem of Tonekabon female students. ProcediaSocial and Behavioral Sciences 84; 2013, 914-918.

[37] Ghazavi Z, Feshangchi S, Alavi M, \& Keshvari M. Effect of a Family-Oriented Communication Skills Training Program on Depression, Anxiety, and Stress in Older Adults. A Randomized Clinical Trial. Nurs Midwifery Stud. 2016; 5 (1). 129-140.

[38] Thomas, H., \& Franz X, B., Drug Prevention by increasing self-esteem. influence of teaching approaches and gender on different consumption groups, World Journal of Education 2013; 3 (1). 1-12.

[39] Jahanbin, I., Bazrafshan, M. R., Akbari, K., Rahmati, M., \& Ghadakpour, S., The effect of life skills training on social communication of clients referring to drug abuse clinics, Jundishapur J Chronic Dis Care. 2017; 31. e13798.

[40] Pujar, L. L \& Patil, S, S. Life Skill Development. Educational Empowerment of Adolescent Girls, RA Journal of Applied Research, 2016; 2 (5). 268-272.

[41] Jamali, S., Sabokdast, S., Sharif Nia, H., Goudarzian, A. H., Beik, S., Allen, K. A. The Effect of Life Skills Training on Mental Health of Iranian Middle School Students. A Preliminary Study. Iran J Psychiatry. 2016; 11 (4). 269-72. [PubMed. 28050189].

[42] Luna-Adame, M., Carrasco-Gimenez, T. J., Rueda-Garcia, M. M. Evaluation of the effectiveness of a smoking prevention program based on the 'Life Skills Training' approach. Health Educ Res. 2013; 28 (4). 673-82. Doi: 10.1093/her/cyt061. [PubMed.23784075]

[43] Bagheri, M. The Role of Life Skills in Attitude Towards Narcotic Drugs and Students' Self-Esteem. Res Addict. 2003; 1 (3). 149-72. 